\title{
Effect of Volume Expansion on Hemodynamics of the Hypoperfused Rat Kidney
}

\author{
Paul A. Johnston, David B. Bernard, John F. Donohoe, Nancy S. Perrin, and \\ Norman G. LevinSKy, Evans Memorial Department of Clinical Research and \\ Department of Medicine, Boston University Medical Center, Boston, \\ Massachusetts 02118
}

A B S T RACT The hemodynamics of the rat kidney were studied during reduction of renal arterial pressure to $35-40 \mathrm{~mm} \mathrm{Hg}(\mathrm{H})$, and after volume expansion at that pressure with $0.9 \% \mathrm{NaCl}$ (IS), $1.7 \% \mathrm{NaCl}$ (HS), $5 \%$ mannitol in $0.9 \% \mathrm{NaCl}$ (MS), $5 \%$ mannitol in water (MW), or $50 \mathrm{mM}$ mannitol $+125 \mathrm{mM} \mathrm{NaCl}$. During $\mathrm{H}$, left renal blood flow (RBF) was $0.8 \pm 0.1 \mathrm{ml} / \mathrm{min}$. Expansion with IS did not alter RBF, but expansion with $\mathrm{HS}, \mathrm{MS}, \mathrm{MW}$, and $50+125 \mathrm{mM} \mathrm{NaCl}$ elevated RBF to $200-250 \%$ of hypoperfusion values. Glomerular capillary pressure rose significantly from $15.7 \pm 0.7 \mathrm{~mm} \mathrm{Hg}$ during $\mathrm{H}$ to $22.3 \pm 1.1,24.4 \pm 0.7$, and $26.6 \pm 0.7 \mathrm{~mm} \mathrm{Hg}$ following expansion with HS, MS, or MW, respectively. Efferent arteriolar pressure also rose significantly to $6.9 \pm 0.5,9.7 \pm 0.8$, and $9.5 \pm 0.9 \mathrm{~mm} \mathrm{Hg}$, respectively. Preglomerular resistance fell to $18-24 \%$ of $\mathrm{H}$ values, and postglomerular resistance fell to $58-74 \%$ of $\mathrm{H}$ values after expansion with HS, MS, or MW. Glomerular filtration (GFR) could not be detected during $\mathrm{H}$ or after IS expansion. HS and mannitol-containing solutions restored GFR to $0.10 \pm 0.02-0.15 \pm 0.02 \mathrm{ml} / \mathrm{min}$, and single nephron glomerular filtration to $6-12 \mathrm{nl} / \mathrm{min}$. Papaverine, acetylcholine, and kinins had no effect on RBF or GFR at a perfusion pressure of $35-40 \mathrm{~mm} \mathrm{Hg}$. We conclude that mannitol and HS have the capacity to augment RBF during hypoperfusion by reducing arteriolar resistance. The mechanism of the rise in RBF is uncertain; it may be due to changes in effective osmolality of the extracellular fluid or to a direct action of mannitol on vascular smooth muscle. Other potent vasodilators were ineffective during hypoperfusion. Restoration of GFR occurs as a result of the combined

Portions of this work were presented to the American Society for Clinical Investigation and appeared in abstract form in 1978. Johnston, P. A., and N. G. Levinsky. Effect of mannitol (M) and $1.7 \%$ saline (HS) on hemodynamics of the hypoperfused kidney. Clin. Res. 26: 543A. (Abstr.)

Received for publication 26 October 1978 and in revised form 16 April 1979. effects of augmented RBF and elevated net filtration pressure.

\section{INTRODUCTION}

The use of mannitol to promote renal function during episodes of ischemia is of both clinical and physiologic interest. Mannitol has been shown to improve hemodynamics and glomerular filtration in several animal models of acute renal failure (1-4). The effectiveness of mannitol treatment in the human syndrome, either prophylactically or therapeutically, is unclear $(5,6)$. However, there would seem to be indications for its use in certain types of human acute renal failure.

Previous studies from our laboratory (7) have focused on the effect of volume expansion with mannitol and saline solutions on the function of the hypoperfused rat kidney, a model of "prerenal failure." This animal model may provide meaningful information about the pathogenesis of acute renal failure not available from the more widely used models in which failure is already fully developed. Our initial observations demonstrated that volume expansion during reduced perfusion with mannitol and hypertonic saline restored the glomerular filtration rate $(\mathrm{GFR})^{1}$ and urine flow $(\dot{\mathrm{V}})$, but expansion with isotonic saline was ineffective. One explanation for this was the expansion with mannitol and hypertonic saline reduced renal vascular resistance (RVR), allowing renal blood flow to rise, and thereby aiding in restoration of the GFR. Studies in hydropenic animals $(8-13)$, and in other animal models

\footnotetext{
${ }^{1}$ Abbreviations used in this paper: $50 \mathrm{M}+125 \mathrm{NaCl}, 50 \mathrm{mM}$ mannitol + $125 \mathrm{mM} \mathrm{NaCl}$; GFR, glomerular filtration rate; HS, $1.7 \% \mathrm{NaCl}$; IS, $0.9 \% \mathrm{NaCl}$; MS, $5 \%$ mannitol in $0.9 \%$ $\mathrm{NaCl} ; \mathrm{MW}, 5 \%$ mannitol in water; $\Delta \mathrm{P}_{\mathrm{a}}, \mathrm{RPP}-\mathrm{P}_{\mathrm{GC}} ; \Delta \mathrm{P}_{\mathrm{e}}, \mathrm{P}_{\mathrm{GC}}-\mathrm{P}_{\mathrm{EA}}$; $P_{E A}$, end efferent arteriolar pressure; $P_{G C}$, glomerular capillary pressure; $\pi_{\mathrm{a}}$, arterial plasma oncotic pressure; RBF, renal blood flow to the left kidney; RPP, renal perfusion pressure; RVR, renal vascular resistance; SNGFR, single nephron glomerular filtration rate; $\hat{V}$, urine flow rate.
} 
of acute renal failure (1-4), have shown that treatment with mannitol leads to a reduction of RVR at normal or nearly normal perfusion pressures. However, little is known about the effects of mannitol or other expansion solutions on the hemodynamics of severely hypoperfused kidneys.

The purpose of the present study was ( $a$ ) to examine the effect of severe hypoperfusion on renal hemodynamics, $(b)$ to determine the effect of volume expansion with mannitol and saline solutions on renal blood flow to left kidney (RBF), RVR, and intrarenal distribution of RBF, and $(c)$ to localize the site of microvascular change in response to volume expansion. We have found that RVR during extreme hypoperfusion is increased. Expansion with mannitol-containing solutions and hypertonic saline increased $\mathrm{RBF}$ principally by reducing preglomerular resistance. As in our previous study, we observed that mannitol and hypertonic saline restored GFR. Increased RBF and concomitant increases in net filtration pressure presumably account for this improvement in filtration.

\section{METHODS}

Munich-Wistar and Charles River rats (Charles River Breeding Laboratories, Inc., Wilmington, Mass.) weighing 150-320 g were anesthetized intraperitoneally with ketamine hydrochloride $(100 \mathrm{mg} / \mathrm{kg})$ and inactin $(20 \mathrm{mg} / \mathrm{kg})$. The animals were placed on a heated animal board, and a tracheostomy was performed. Catheters were placed in the left jugular vein for infusion of fluids, and in the femoral artery for sampling of blood and monitoring of renal perfusion pressure (RPP). The left kidney was isolated through a suprapubic incision, and both ureters were catheterized. An adjustable clamp was placed around the descending aorta above both renal arteries so that perfusion pressure to the kidneys could be regulated.

Four series of animals were studied. In the first series, RBF and GFR were assessed in both Munich-Wistar and Charles River rats during reduction in RPP and after volume expansion during reduced perfusion. As the results from both types of rat were not different, the data have been combined. After a control period during which isotonic saline was infused at a rate of $0.03 \mathrm{ml} / \mathrm{min}, \mathrm{RPP}$ was reduced to $35-40 \mathrm{~mm} \mathrm{Hg}$. After 30 min of equilibration, the animals received an infusion of one of the following solutions: $0.9 \% \mathrm{NaCl}$ (IS), $1.7 \% \mathrm{NaCl}$ (HS), $5 \%$ mannitol in $0.9 \% \mathrm{NaCl}$ (MS), $5 \%$ mannitol in water (MW), or $50 \mathrm{mM}$ mannitol $+125 \mathrm{mM} \mathrm{NaCl}(50 \mathrm{M}+125 \mathrm{NaCl})$ at $1.0 \mathrm{ml} / \mathrm{min}$ until a volume equivalent to $3-5 \%$ of body wt had been administered. Subsequently, the infusion rate was reduced to $0.1 \mathrm{ml} / \mathrm{min}$, and continued at the rate throughout the remainder of the experiment. Perfusion pressure was maintained at $35-40 \mathrm{~mm} \mathrm{Hg}$. $10-15 \mathrm{~min}$ after the infusion rate had been decreased, urine collection was begun. Blood flow in the left renal artery was measured continuously by small diameter flow probe (EP model 401.5; Carolina Medical Electronics, Inc., King, N. C.) connected to a square wave electromagnetic flowmeter (model 501, Carolina Medical Electronics, Inc.). The flowmeter system was calibrated in vitro by perfusing a segment of femoral artery with whole blood. The response of this system was linear over a range of flow from 0.5 to $10.0 \mathrm{ml} / \mathrm{min}$. The flowmeter was also assessed in vivo by comparing measurements made with this system to RBF determined from the clearance of $\left[{ }^{3} \mathrm{H}\right] p$ aminohippuric acid (13). In seven rats, the mean difference between the measurements was $0.23 \pm 0.11 \mathrm{ml} / \mathrm{min}$ (SE). This was not statistically significant, and was $<5 \%$ of the mean control values of $\mathrm{RBF}$. In addition, $\mathrm{RBF}$ was measured by clearance and extraction of $\left[{ }^{3} \mathrm{H}\right] p$-aminohippuric acid before and after positioning of the probe around the left renal artery. Blood flow, after the probe had been positioned, was $99 \pm 7 \%$ of the flow before positioning the probe. These data indicate that direct measurement of RBF by the flowmeter system is comparable to estimates of RBF by clearance techniques, and that the process of positioning the probe around the renal artery does not significantly alter hemodynamics. In addition, the effect of changes in hematocrit on RBF measurement was assessed by perfusing the in vitro calibration system with blood of varying hematocrits. Variation of hematocrit over the range of 40 to $50 \%$ (similar to that observed in the following experiments) resulted in a maximum change of $\mathrm{RBF}$ of 0.15 $\mathrm{ml} / \mathrm{min}$. Inasmuch as this change borders on the limit of accuracy of the flowmeter system, blood flows obtained during the experiments were not corrected for changes in hematocrit.

Whole kidney GFR was estimated from the clearance of $\left[{ }^{14} \mathrm{C}\right]$ inulin (New England Nuclear, Boston, Mass.), and single nephron glomerular filtration (SNGFR) was estimated from timed collection of proximal tubule fluid and tubule fluid: systemic plasma $\left[{ }^{14} \mathrm{C}\right]$ inulin concentration ratios. In some instances it was impossible to collect tubule fluid. Under these circumstances the occurrence of filtration was assessed qualitatively by observing the passage of lissamine green dye into tubules.

The effect of hypoperfusion and volume expansion during hypoperfusion on renal microvascular pressures and arteriolar resistance was assessed in a second series of rats (MunichWistar only). Hydrostatic pressures in the glomerular capillary $\left(P_{G C}\right)$ and at the end of the efferent arteriole $\left(P_{E A}\right)$ were measured during hypoperfusion, and after expansion with IS, HS, MS, or MW. End efferent arteriolar pressures were measured directly with a servo-null device $(14,15)$. Two methods were used to estimate $\mathrm{P}_{\mathrm{Gc}}$. Direct puncture of surface glomeruli (15) was carried out with a micropipette (2- to $3-\mu \mathrm{m}$ tip diameter) attached to a servo-null system. The pipette was filled with $1 \mathrm{M}$ saline lightly colored with lissamine green dye. Because of the lack of the pulsatile pressure in glomerular capillaries at RPP of $<40 \mathrm{~mm} \mathrm{Hg}$, the pattern of dye perfusion when injected from the micropipette was used to determine the position of the pipette tip in the capillary. If the dye was expelled with very little pressure and passed quickly from the glomerular structure, it was concluded that the pipette was poorly placed. A second factor used to indicate proper positioning of the pipette was a stable pressure recording for 20-30 s.

In addition to the direct puncture technique, $\mathrm{P}_{\mathrm{GC}}$ was estimated from stop-flow pressures and arterial plasma oncotic pressure. Oncotic pressure $\left(\pi_{\mathrm{a}}\right)$ was calculated from plasma protein concentration by the formula $\pi_{\mathrm{a}}=(1.52+0.35 \mathrm{M}) \mathrm{C}_{\mathrm{a}}$ $+(0.234+0.009 / M) C_{a}{ }^{2}(16)$, in which $M$ is the molarity of the fluid containing the protein (in this case, $0.15 \mathrm{M}$ ) and $\mathrm{C}_{\mathrm{a}}$ is the plasma protein concentration. Plasma protein concentration was measured by the Lowry technique (17). Glomerular capillary pressure was estimated by the formula $\mathrm{P}_{\mathrm{GC}}=\pi_{\mathrm{a}}$ $+\mathrm{SFP}$, in which SFP equals the stop-flow pressure in the earliest convolution of the proximal tubule. The stop-flow pressure was the stable hydrostatic pressure achieved in the earliest accessible proximal convoluted tubule $2 \mathrm{~min}$ after blocking the nephron distally with castor oil (18). Direct measurement and stop-flow estimates of $P_{G C}$ were compared in six animals after volume expansion during hypoperfusion with MS, and in one animal expanded with HS during hypo- 


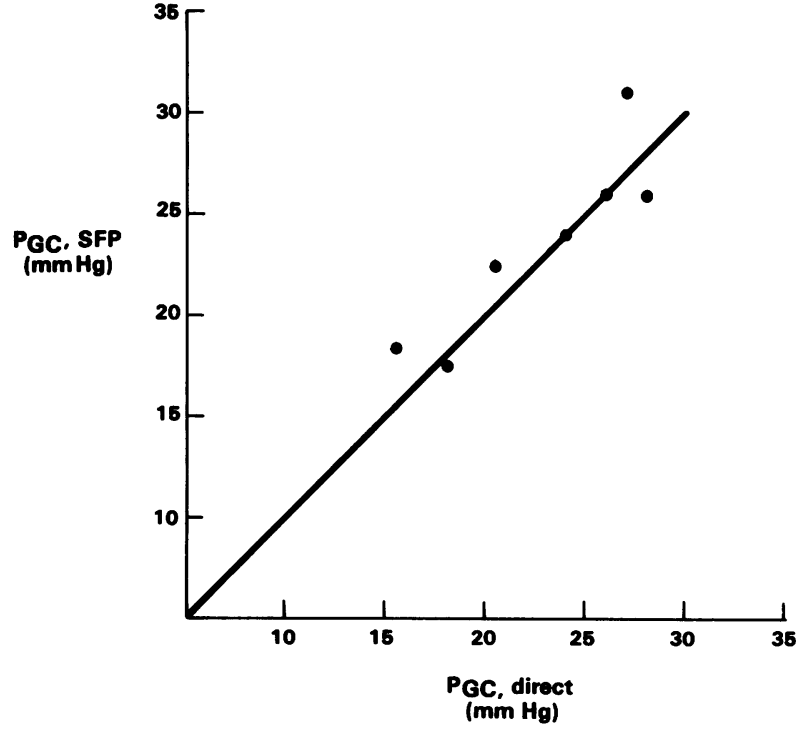

Figure 1 Comparison of measurement of $\mathrm{P}_{\mathrm{GC}}$ by direct puncture of surface glomeruli $\left(\mathrm{P}_{\mathrm{GC}}\right.$, direct) and by stop-flow techniques $\left(\mathrm{P}_{\mathrm{GC}}, \mathrm{SFP}\right)$. Solid line is the line of identity. Mean difference $\left(\mathrm{P}_{\mathrm{GC}}\right.$, direct $\left.\mathrm{P}_{\mathrm{GC}}, \mathrm{SFP}\right)$ was $0.66 \pm 0.93 \mathrm{~mm} \mathrm{Hg}$ $(P>0.40, n=7)$.

perfusion. The mean difference between the two techniques was $0.66 \pm 0.93 \mathrm{~mm} \mathrm{Hg}$ (Fig. 1). Thus, under the conditions of this study, estimates of $\mathbf{P}_{\mathrm{GC}}$ determined by direct puncture or stop-flow were comparable.

Changes in pre- and postglomerular resistance following volume expansion were estimated by calculated values for pre- and postglomerular pressure gradients determined from the second series of animals, and measured changes in RBF determined from the first series of animals. The following equation was used to calculate resistance changes of pre- or postglomerular segments:

$$
\mathbf{R}_{v e}{ }^{a} / R_{h}{ }^{a}=\left(\Delta P_{v e}{ }^{a} / \Delta P_{h}{ }^{a}\right) \cdot\left(Q_{h} / Q_{v e}\right) .
$$

$R_{v e}{ }^{a} / R_{h}{ }^{a}$ represents the relative resistance change of the pre- or postglomerular arteriole following volume expansion compared with that in hypoperfusion; $\Delta \mathbf{P}_{v e}{ }^{a}$ and $\Delta \mathbf{P}_{h}{ }^{a}$ are the pressure gradients $\Delta \mathrm{P}_{\mathrm{a}}$ or $\Delta \mathrm{P}_{\mathrm{e}}$ across the pre- or postglomerular arteriole during volume expansion or hypoperfusion; and $Q_{h}$ and $Q_{v e}$ are the blood flows in the left renal artery during volume expansion or hypoperfusion.

In a third series of animals (Charles River), RBF distribution to the outer cortex was determined during hypoperfusion and after volume expansion with MS, HS, and IS. The left kidney was prepared as previously described. Microspheres (19), $15 \mu \mathrm{m}$ in diameter, labeled either with ${ }^{141} \mathrm{Ce}$ or ${ }^{103} \mathrm{Ru}$, were suspended in $0.9 \% \mathrm{NaCl}$ and $0.05 \%$ Tween 80 (Tween Emulsifiers, ICI United States, Inc., Wilmington, Del.). A 0.15$\mathrm{ml}$ bolus of the suspension, containing $\cong 4 \times 10^{5}$ spheres labeled with ${ }^{141} \mathrm{Ce}$, was injected during hypoperfusion through a catheter placed in the left carotid artery. A second $0.15-\mathrm{ml}$ bolus containing ${ }^{103} \mathrm{Ru}$-labeled spheres was administered 10 min after volume expansion. The experimental kidney was then excised, its capsule was removed, and it was sectioned sagittally. Each section was placed cut-face down on a Stadie-Riggs microtome, and a $0.5-\mathrm{mm}$ slice removed. The slices from the two halves were considered to be duplicates of the outer cortical zone. For each isotope, the cpm per gram outer cortical tissue was compared to the cpm per gram of total kidney. Kidneys were discarded in which there was a difference of $>20 \%$ in this ratio between duplicate outer cortical slices. A reduction in the ratio (outer cortex:whole kidney) for the isotope given after volume expansion, ${ }^{103} \mathrm{Ru}$, compared with that given before, ${ }^{141} \mathrm{Ce}$, would indicate a redistribution of RBF away from the outer cortex.

A fourth group of rats (both Munich-Wistar and Charles River) was studied to assess the effect of known vasodilators on RBF at low perfusion pressure. After $30 \mathrm{~min}$ of hypoperfusion, either papaverine $(0.1-2.0 \mu \mathrm{g} / \mathrm{min})$, acetylcholine (2-40 $\mu \mathrm{g} / \mathrm{min}$ ), or kinin (bradykinin or kallidin, 0.25-2.4 $\mu \mathrm{g} / \mathrm{min}$ ) were infused into the renal artery through a siliconized glass micropipette (25- $\mu \mathrm{m}$ tip diameter). Care was taken to assure adequate infusion. Left renal blood flow was monitored continuously with a flowmeter.

One-way and multifactorial analysis of variance tests (20) were used to determine the significance of the change in RBF and superficial vascular hydrostatic pressures following volume expansion. The significance of the difference between mean experimental response and control group was evaluated by a Dunnett's test of multiple treatment means vs. control (21). Data are reported as mean \pm SE. A $P<0.05$ was considered significant.

\section{RESULTS}

Effect of hypoperfusion and volume expansion on $R B F$ and $R V R$. In 35 rats, RBF during hydropenia was $5.4 \pm 0.2 \mathrm{ml} / \mathrm{min}$, and RPP averaged $105 \pm 2 \mathrm{~mm} \mathrm{Hg}$. When RPP was reduced to $36 \pm 1 \mathrm{~mm} \mathrm{Hg}, \mathrm{RBF}$ fell to 0.8 $\pm 0.1 \mathrm{ml} / \mathrm{min}$. Total renal vascular resistance (RVR $=\mathrm{RPP} / \mathrm{RBF}$ ) was $53.1 \pm 3.2 \mathrm{~mm} \mathrm{Hg} / \mathrm{ml}$ per min during hypoperfusion, a value significantly greater than that of $20.7 \pm 0.7 \mathrm{~mm} \mathrm{Hg} / \mathrm{ml}$ per min observed during hydropenia $(P<0.001)$. Table I shows the effect of volume expansion with five different solutions on plasma protein concentration and hematocrit. Treatment with these solutions resulted in a nearly comparable degree of expansion, as judged from these changes. The effect of saline and mannitol infusion on RBF is shown in Fig. 2.

TABLE I

Effect of Volume Expansion on Plasma Protein Concentration and Hematocrit

\begin{tabular}{ccl}
\hline & Protein & Hematocrit \\
\hline & g/dl & \multicolumn{1}{c}{$\%$} \\
Hypoperfusion & $4.9 \pm 0.1$ & $49.3 \pm 1.0$ \\
& $(n=33)$ & $(n=35)$ \\
$0.9 \% \mathrm{NaCl}$ & $3.1 \pm 0.2$ & $44.8 \pm 2.9$ \\
& $(n=10)$ & $(n=8)$ \\
$1.7 \% \mathrm{NaCl}$ & $2.7 \pm 0.1$ & $45.1 \pm 1.3$ \\
& $(n=11)$ & $(n=10)$ \\
$5 \%$ mannitol in & $2.8 \pm 0.1$ & $43.6 \pm 1.1$ \\
$0.9 \% \mathrm{NaCl}$ & $(n=14)$ & $(n=8)$ \\
$5 \%$ mannitol in & $3.3 \pm 0.1$ & $46.1 \pm 1.7$ \\
water & $(n=7)$ & $(n=9)$ \\
50 mM Mannitol & $3.6 \pm 0.1$ & $42.0 \pm 1.4$ \\
+125 mM NaCl & $(n=10)$ & $(n=5)$ \\
\hline
\end{tabular}






FIGURE 2 Effect of volume expansion during hypoperfusion on RBF. RBF during hypoperfusion was $0.8 \pm 0.1 \mathrm{ml} / \mathrm{min}$. Data are mean $\pm S E$. ${ }^{*} P<0.005$ vs. hypoperfusion.

Volume expansion with IS during the period of reduced RPP did not significantly alter RBF. However, expansion with $\mathrm{HS}, \mathrm{MS}, \mathrm{MW}$, or $50 \mathrm{M}+125 \mathrm{NaCl}$ elevated RBF significantly to more than twice hypoperfusion levels $(P<0.01$ for each infusate). Because RPP was constant, calculated RVR fell significantly to $47.7 \pm 4.2$, $43.3 \pm 5.4,49.5 \pm 7.6$, and $49.8 \pm 3.3 \%$ of hypoperfusion levels following expansion with HS, MS, MW, and $50 \mathrm{M}$ $\pm 125 \mathrm{NaCl}$, respectively $(P<0.01$ for each infusate) .

Effect of volume expansion during hypoperfusion on $\dot{V}, G F R$, and SNGFR. $\dot{V}$ during hydropenia was 1.98 $\pm 0.23 \mu \mathrm{l} / \mathrm{min}(n=20$ tubules $)$, GFR averaged $0.95 \pm 0.1$ $\mathrm{ml} / \mathrm{min}(n=1$ tubule), and SNGFR was $28.5 \pm 1.3 \mathrm{nl} /$ $\min (n=15$ tubules). During hypoperfusion there was no $\dot{V}$, and lissamine green dye did not enter the proximal tubule, indicating that filtration was minimal or absent. The effects of volume expansion are shown in Fig. 3. Urine flow was not restored by IS; proximal tubules remained collapsed and lissamine green dye failed to appear in surface nephrons. Thus, filtration remained very low or absent. Urine flow was restored in 8 of 11 rats after volume expansion with HS, and GFR in these animals was about $10 \%$ of hydropenic values. SNGFR could not be quantified because proximal tubule flow rate was too low to permit adequate collection of fluid. However, lissamine green dye passed into proximal tubules in all eight rats that made urine, and in one of three that remained anuric. Volume expansion with each of the mannitol solutions restored $\dot{\mathrm{V}}$, although the $50 \mathrm{M}+125 \mathrm{NaCl}$ solution did not generate as large an increase in $\dot{V}$ as MS or MW. GFR was equally restored by all the mannitol solutions to about $17 \%$ of hydropenic values. SNGFR ranged from 6-12 $\mathrm{nl} / \mathrm{min}$ with these same solutions.

Effect of volume expansion on microvascular pressures and arteriolar resistance. In the second series of animals, microvascular pressures were assessed during hypoperfusion, before and after volume expansion (Table II, Fig. 4). $\mathrm{P}_{\mathrm{GC}}$ was $15.7 \mathrm{~mm} \mathrm{Hg}$ during hypoperfusion and $\pi_{\mathrm{a}}$ was $14.3 \mathrm{~mm} \mathrm{Hg}$. Therefore, the net filtration pressure at the afferent end of the glomerular capillary was near zero. ${ }^{2}$ Efferent arteriolar pressure was $4.6 \mathrm{~mm} \mathrm{Hg}$. The $\Delta \mathrm{P}_{\mathrm{a}}\left(\mathrm{RPP}-\mathrm{P}_{\mathrm{GC}}\right)$ was 20.9 $\mathrm{mm} \mathrm{Hg}$, and the $\Delta \mathrm{P}_{\mathrm{e}}\left(\mathrm{P}_{\mathrm{GC}}-\mathrm{P}_{\mathrm{EA}}\right)$ was $11.0 \mathrm{~mm} \mathrm{Hg}$. Volume expansion with IS had no effect on $\mathrm{P}_{\mathrm{GC}}$, but $P_{\mathrm{EA}}$ increased significantly to $8.6 \mathrm{~mm} \mathrm{Hg}(P<0.01)$. Pre- and postglomerular pressure gradients were not significantly different from those during hypoperfusion. After volume expansion with $\mathrm{HS}, \mathrm{MS}$, or $\mathrm{MW}, \mathrm{P}_{\mathrm{GC}}$ rose significantly to 7-9 $\mathrm{mm} \mathrm{Hg}(P<0.01)$. The preglomerular pressure gradient fell significantly to $10-13 \mathrm{~mm}$ $\mathrm{Hg}$ after these infusions $(P<0.05)$. Net filtration pressure $\left(\mathrm{P}_{\mathrm{Gc}}-\pi_{\mathrm{a}}-\mathrm{P}_{\mathrm{t}}\right)$ at the afferent end of the glomerulus rose to $6.0 \pm 1.3,8.4 \pm 1.1$, and $8.1 \pm 1.0 \mathrm{~mm} \mathrm{Hg}$ after expansion with HS, MS, and MW, respectively. Proximal tubule pressure was not measurable after expansion with IS. The difference between $\mathrm{P}_{\mathrm{Gc}}$ and $\pi_{\mathrm{a}}$ was 8.0 $\pm 0.8 \mathrm{~mm} \mathrm{Hg}$ in four animals expanded with IS. As most proximal tubules appeared collapsed after this expansion,

\footnotetext{
${ }^{2}$ Proximal tubules were completely collapsed preventing pressure measurements. We assumed tubular pressure was very low and, therefore, not a factor in determining net afferent filtration pressure.
} 


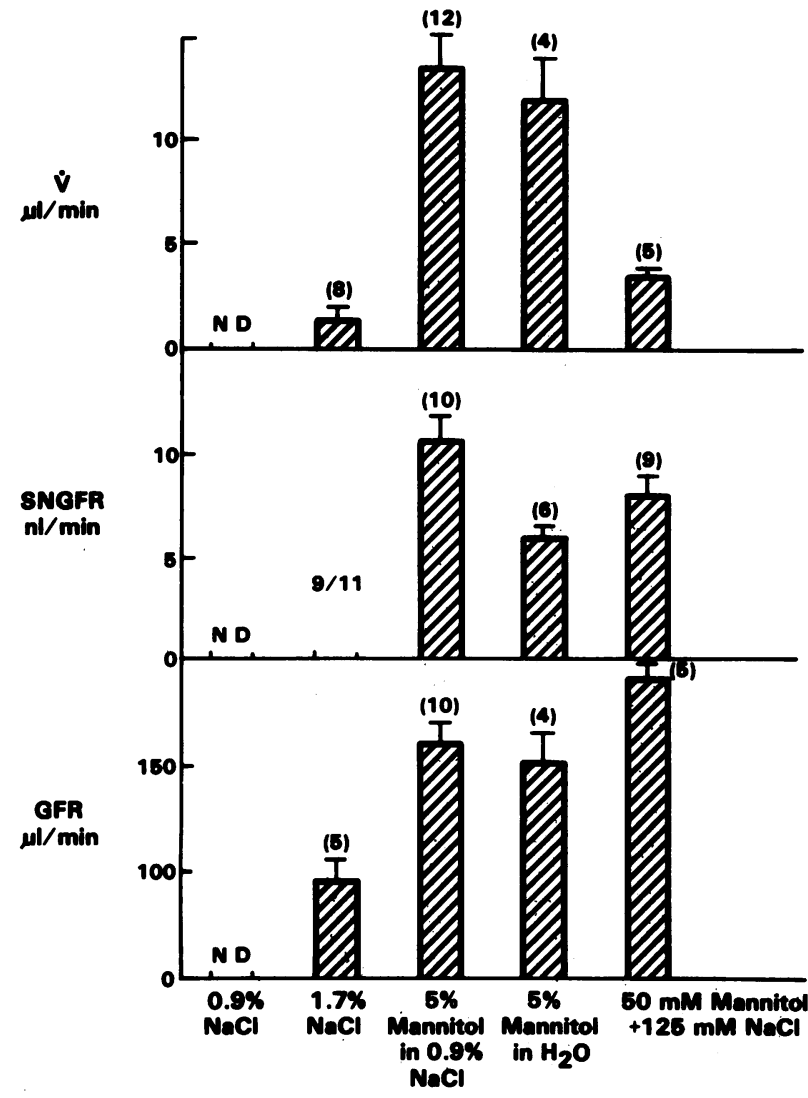

FIGURE 3 The effect of volume expansion during hypoperfusion on whole kidney GFR, SNGFR, and $\dot{V}$. Numbers in parentheses represent number of animals in which that variable was assessed. ND indicates that the variable could not be determined under the described condition. The notation 9/11 indicates that SNGFR was qualitatively observed in 9 of 11 animals after expansion with HS. Data are mean $\pm S E$.
$\mathrm{P}_{\mathrm{Gc}}-\pi_{\mathrm{a}}$ is probably a reasonable approximation of the net filtration pressure at the afferent end of the glomerulus.

There was a small, but statistically significant effect of volume expansion with MS and HS on RBF distribution to the outer cortex of the left kidney (Table III). The number of microspheres in outer cortical tissue relative to whole kidney tissue fell about $13 \%$ following expansion with these solutions. Expansion with IS, however, did not appear to affect the sphere distribution. From these results we concluded that outer cortical blood flow increased only slightly less than total RBF. These small alterations in distribution, even though significant, would have a minor effect on calculated arteriolar resistance changes. Therefore, we chose not to correct our resistance data as presented below.

Volume expansion with IS did not significantly affect calculated pre- or postglomerular resistance. However, calculated preglomerular resistance fell dramatically to $18-27 \%$ of hypoperfusion values after volume expansion with HS, MS, or MW. Postglomerular resistance fell to $58-74 \%$ of hypoperfusion values after expansion with these same solutions (Table IV). These results have not been corrected for the effect of changes in SNGFR on blood flow through the efferent arteriole. Therefore, changes in postglomerular resistance are actually less than indicated in Table IV.

Effect of vasodilators in RBF of the hypoperfused kidney. To ascertain whether or not the effect of mannitol or HS was mediated by a mechanism similar to that underlying the renal hemodynamic effect of other known vasodilators, the response of the renal vasculature to infusion during hypoperfusion of several of these vasodilators was assessed. Acetylcholine, papav-

TABLE II

Microvascular Hemodynamics during Hypoperfusion and after Volume Expansion

\begin{tabular}{|c|c|c|c|c|c|c|}
\hline & RPP & $\mathbf{P}_{\mathbf{G C}}$ & $\mathbf{P}_{\mathrm{EA}}$ & $\pi_{\mathrm{a}}$ & $\mathrm{P}_{\mathrm{t}}^{*}$ & $n \ddagger$ \\
\hline & \multicolumn{6}{|c|}{$m m \mathrm{Hg}$} \\
\hline Hypoperfusion & $37 \pm 1$ & $15.7 \pm 0.7$ & $4.6 \pm 0.3$ & $14.3 \pm 0.4$ & $0 \S$ & 6 \\
\hline Number of observations & 6 & 10 & 8 & 3 & & \\
\hline $0.9 \% \mathrm{NaCl}$ & $38 \pm 1$ & $16.6 \pm 0.8$ & $8.6 \pm 0.7^{\prime \prime}$ & $9.3 \pm 0.5^{\prime \prime}$ & $0 \$$ & 5 \\
\hline Number of observations & 5 & 14 & 16 & 5 & & \\
\hline $1.7 \% \mathrm{NaCl}$ & $36 \pm 1$ & $22.3 \pm 1.1^{11}$ & $6.9 \pm 0.5$ & $7.0 \pm 0.3^{\prime \prime}$ & $9.5 \pm 0.6$ & 6 \\
\hline Number of observations & 6 & 19 & 9 & 7 & 15 & \\
\hline $5 \%$ mannitol in $0.9 \% \mathrm{NaCl}$ & $36 \pm 1$ & $24.4 \pm 0.7^{11}$ & $9.7 \pm 0.8^{\prime \prime}$ & $7.0 \pm 0.2$ & $8.8 \pm 0.6$ & 11 \\
\hline Number of observations & 11 & 38 & 10 & 16 & 15 & \\
\hline $5 \%$ mannitol in water & $37 \pm 1$ & $26.6 \pm 0.7^{11}$ & $9.5 \pm 0.9^{\prime \prime}$ & $9.4 \pm 0.3$ & $10.7 \pm 0.6$ & 5 \\
\hline Number of observations & 5 & 15 & 7 & 8 & 8 & \\
\hline
\end{tabular}

Mean \pm SE.

* Proximal tubule pressure.

\$ Number of animals studied in each group.

$\S$ Most tubules collapsed; pressure presumed to be near zero.

" $P<0.01$ vs. hypoperfusion.

II $P<0.05$ vs. hypoperfusion. 


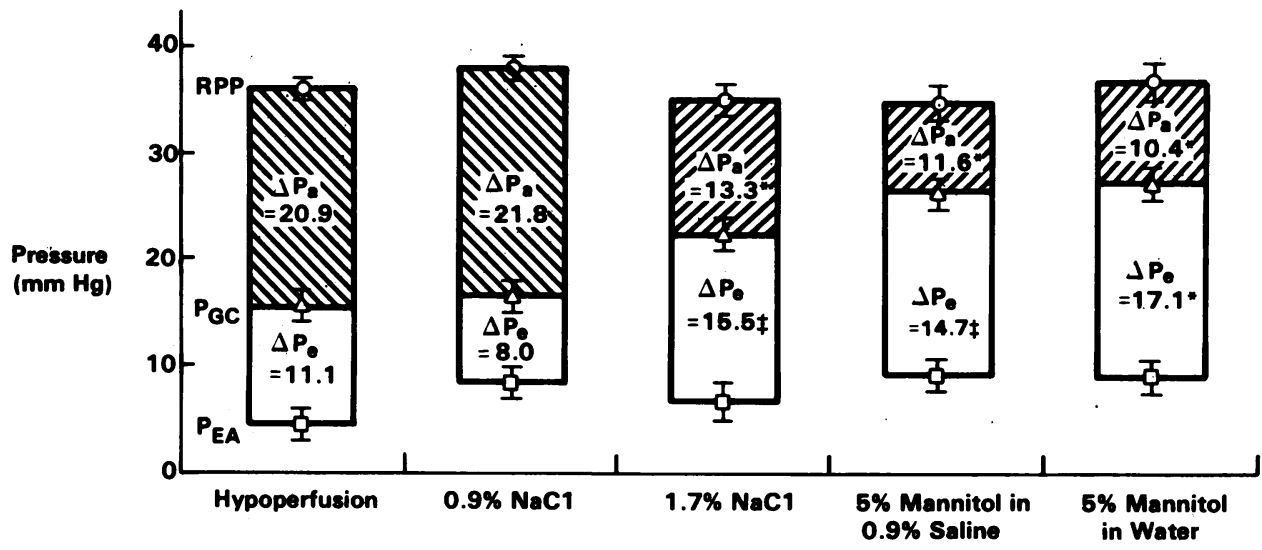

FIGURE 4 Effect of volume expansion with four different solutions during hypoperfusion on RPP (O), $\mathbf{P}_{\mathrm{GC}},(\Delta)$ and $\mathbf{P}_{\mathrm{EA}}(\square)$. The length of the hatched portion of the bar represents $\Delta \mathbf{P}_{\mathrm{a}}$ $\left(R P P-P_{G C}\right)$, and the length of the open portion represents $\Delta P_{e}\left(P_{G C}-P_{E A}\right)$. Mean values for $\Delta P_{a}$ and $\Delta \mathrm{P}_{\mathrm{e}}$ are indicated in the appropriate portion of the box. ${ }^{* P}<0.01 ; \$ P<0.05$ compared with hypoperfusion. The absence of a symbol indicates not significant compared with hypoperfusion.

erine, or kinins were infused directly into the left renal artery of normally perfused and hypoperfused kidneys. In doses that increased RBF by $15-20 \%$ in normally perfused kidneys, these agents had no effect on RBF of hypoperfused kidneys.

\section{DISCUSSION}

This study provides the first evaluation of the effects of severe hypoperfusion and subsequent volume expansion on renal hemodynamics and microvascular pressures. Our previous study (7) described the effect of hypoperfusion and subsequent volume expansion on GFR. However, because of the limitation of available technology at the time, we were unable to directly assess changes in hemodynamic factors. Discovery of the Munich-Wistar rat, with accessible surface glomeruli, and the advent of instrumentation, such as a small electromagnetic flow probe (13) and the servo-null pressure measuring device $(14,15)$, have enabled us to evaluate critically changes in $\mathrm{RBF}$, vascular resistance, and arteriolar resistance in the hypoperfused kidney.

TABLE III

Effect of Volume Expansion on the Distribution of Radioactive Microspheres in the Outer Cortex

\begin{tabular}{lll}
\hline & Hypoperfusion & Volume expansion \\
\hline $0.9 \% \mathrm{NaCl}(n=5)$ & $1.70 \pm 0.14$ & $1.60 \pm 0.06$ \\
$1.7 \% \mathrm{NaCl}(n=5)$ & $1.91 \pm 0.09$ & $1.66 \pm 0.11^{*}$ \\
$5 \%$ mannitol in $0.9 \% \mathrm{NaCl}$ & $1.74 \pm 0.05$ & $1.52 \pm 0.03 \ddagger$ \\
$\quad(n=11)$ & & \\
\hline
\end{tabular}

Data are (cpm/gram outer cortex $\div$ cpm/gram whole kidney); mean $\pm S E$.

${ }^{*} P<0.005$.

$\ddagger P<0.005$.
Renal vascular resistance of rat kidneys perfused at $<40 \mathrm{~mm} \mathrm{Hg}$ for $30 \mathrm{~min}$ was significantly greater than RVR of normally perfused kidneys. These results are not necessarily in conflict with previous autoregulation studies (22-27), which show that RVR decreases during progressive hypoperfusion. In most of those studies, observations were only made above a perfusion pressure at which urine flow ceases $(55-60 \mathrm{~mm} \mathrm{Hg})$. Additionally, most observations were made only after a short period of hypoperfusion at a reduced pressure. A recent study by Arendshorst et al. (13) employing the electromagnetic flow probe in the rat, demonstrated a tendency for RVR to rise as RPP was reduced below $65 \mathrm{~mm} \mathrm{Hg}$. Studies in anesthetized dogs demonstrate that RVR is greater at low perfusion pressure than at normal pressures $(28,29)$. These observations, together with previous studies of renal autoregulation, suggest

TABLE IV

Effect of Volume Expansion on Pre- and Postglomerular Resistance of the Hypoperfused Kidney

\begin{tabular}{lcc}
\hline & $\begin{array}{c}\text { Preglomerular } \\
\text { resistance }\end{array}$ & $\begin{array}{c}\text { Postglomerular } \\
\text { resistance }\end{array}$ \\
\hline $0.9 \% \mathrm{NaCl}$ & $103 \pm 5$ & $84.0 \pm 10$ \\
& $(n=4)$ & $(n=4)$ \\
$1.7 \% \mathrm{NaCl}$ & $26.8 \pm 3.3^{*}$ & $59.8 \pm 7.2 \ddagger$ \\
& $(n=6)$ & $(n=5)$ \\
$5 \%$ mannitol in $0.9 \% \mathrm{NaCl}$ & $19.4 \pm 2.7^{*}$ & $73.8 \pm 1.5 \S$ \\
& $(n=11)$ & $(n=4)$ \\
$5 \%$ mannitol in water & $18.3 \pm 2.9^{*}$ & $57.5 \pm 9.3 \S$ \\
& $(n=5)$ & $(n=3)$ \\
\hline
\end{tabular}

Data are mean $\pm \mathrm{SE}$ percent of hypoperfusion values.

$* P<0.001$ compared with $100 \%$.

t $P<0.005$ compared with $100 \%$.

$\S P<0.01$ compared with $100 \%$. 
that above a perfusion pressure of $80-100 \mathrm{~mm} \mathrm{Hg}$, RVR falls in proportion to RPP, maintaining RBF nearly constant. Below the level of autoregulation, in the range of 60-80 mm Hg, RVR remains constant, and thus RBF falls in proportion to RPP. Below about $55 \mathrm{~mm} \mathrm{Hg}$, however, RVR may rise, causing RBF to fall to a greater degree than RPP.

Volume expansion during reduced perfusion with mannitol-containing solutions or HS led to a large reduction in renal vascular resistance. The major site of resistance change accompanying volume expansion was preglomerular. There was also some alterations in postglomerular resistance, but this change was less marked. From these data we concluded that the vasculature of the hypoperfused rat kidney is not maximally dilated. Previous studies by Robertson et al. (30) also suggest that resistance is not fixed at low perfusion pressures. Isoncotic plasma expansion of rats whose kidneys were being perfused at $60 \mathrm{~mm} \mathrm{Hg}$ resulted in a reduction of calculated capillary resistance and an increase in capillary blood flow compared with rats with the same renal perfusion pressure. In these studies the principal site of resistance change was also preglomerular, whereas efferent arteriolar resistance rose. Likewise, intrarenal infusion of vasodilator substances such as dopamine, acetylcholine, papaverine, and prostaglandin $\mathrm{E}_{2}$ has been shown to cause a reduction in preglomerular resistance in the hypoperfused dog kidney (31), suggesting that RVR is not minimal below the autoregulatory range.

One of the limitations of this model is that during hypoperfusion pre- or postglomerular capillary plasma flow, necessary for calculation of capillary resistance, cannot be measured by standard techniques (32). Direct assessment of capillary plasma flow depends on measurements of SNGFR and efferent arteriolar protein concentration. As demonstrated in this and our previous study (7), SNGFR ceased when RPP was reduced to $40 \mathrm{~mm} \mathrm{Hg}$. Therefore, it was impossible to directly assess changes in blood flow to those nephrons in the superficial cortex in which microvascular pressures were measured. We circumvented this limitation by estimating changes in blood flow to the superficial cortex from changes in the distribution of radiolabeled microspheres. We found that changes in blood flow in the superficial cortex after expansion with MS and HS were approximately the same as changes in total RBF. ${ }^{3}$ However, recent studies (33-35) have suggested that $15 \mu \mathrm{m}$ microspheres may overestimate the effect of

\footnotetext{
${ }^{3}$ As discussed in Results, although the changes in distribution of radioactive microsphere to the outer cortex were small, these did achieve statistical significance. Nevertheless, because distribution changes had little effect on the calculated pre- and postglomerular resistance changes, we treated the data as if the changes in superficial cortical blood flow and total RBF were equal.
}

volume expansion on the distribution of RBF to the superficial cortex. If this were the circumstance in our present study, the change in blood flow to this zone may have been significantly less than estimated using the distribution of microspheres. Nevertheless, even if our analysis of capillary blood flow changes were in error by as much as $30 \%$, the changes in $\mathrm{RBF}, \Delta \mathrm{P}_{\mathrm{a}}$, and $\Delta \mathrm{P}_{\mathrm{e}}$ were such that calculated preglomerular resistance would still have fallen to $27.7 \pm 2.7,38.2 \pm 3.3$, and $26.1 \pm 3.0 \%$ of hypoperfusion values following expansion with MS, HS, and MW, respectively.

Several factors should be considered as possible explanations for the decrease in RVR: $(a)$ the effect of hematocrit on blood viscosity; (b) a nonspecific vasodilator effect of volume expansion; $(c)$ the osmotic properties of the expansion solutions; and $(d)$ a nonosmotic effect of mannitol.

The effect of volume expansion with erythrocyte-free solutions on whole blood viscosity must be considered because calculated vascular resistance is proportional to viscosity (36). The largest changes in hematocrit, and therefore viscosity, occurred after volume expansion with IS (50.8 $\pm 1.8 \%-44.8 \pm 2.9 \%)$ and MS (51.4 $\pm 1.8 \%-$ $43.6 \pm 1.1 \%$ ). Theoretically, this change could have accounted for only $10 \%$ of the observed changes in RBF (37). Additionally, though this effect of expansion on hematocrit was nearly the same with both solutions, expansion with MS caused a significant fall in RVR, whereas expansion with IS resulted in no change in RVR. Therefore, we believe it unlikely that a decrease in viscosity, because of a reduced hematocrit, was an important determinant of the effect of mannitol on RVR in this model.

A nonspecific vasodilator effect of volume expansion is unlikely as a possible mechanism for reduced RVR on the basis of the following observations. Infusion of IS caused a fall in plasma protein concentration nearly equivalent to that which occur after infusion of equal volumes of $\mathrm{HS}$, MS, MW, or $50 \mathrm{M}+125 \mathrm{NaCl}$. This indicates that a comparable degree of extracellular volume expansion was achieved with all five solutions. However, infusion of IS had little effect on renal hemodynamics.

Previous studies $(9,11,12)$ have suggested that increases in extracellular fluid osmolality after infusions of hypertonic mannitol caused renal vasodilation in normally perfused kidneys. Navar et al. (12) have suggested that the effect of hypertonic mannitol in normally perfused kidneys is mediated by a macula densa feedback mechanism that is sensitive to local changes in tubule fluid osmolality. It is unlikely, however, that this mechanism was involved in the vascular response to expansion during hypoperfusion with MS or HS. Neither solute could have entered the renal tubule before the decrease in resistance. As demonstrated in this and our previous study, SNGFR is virtually 
absent during hypoperfusion. However, we cannot rule out an effect of either solution via a macula densa feedback mechanism initiated by alterations in the peritubular environment.

Hypertonic mannitol has also proved effective in improving $\mathrm{RBF}$ in postischemic acute renal failure (1-3, $38-41)$. It was originally postulated that the mechanism of this effect was a reduction in vascular cell swelling by virtue of the effect of increased extracellular osmolality (2). Recently, Frega et al. (3) have demonstrated that vascular swelling may not be an important result of ischemia. However, to determine if reduction of cell swelling by MS or HS played a major role in the observations of the present study, vascular elements from two animals expanded with IS, and two animals expanded with MS were examined by light and electron microscopy. The kidneys from animals expanded with MS were indistinguishable from those expanded with IS. Moreover, vascular elements from these kidneys appeared to be no different than those from normally perfused kidneys of nonexpanded rats. ${ }^{4}$ Although the reduction of minimal cell swelling cannot be ruled out completely, it seems unlikely that the mechanism of reduced resistance is related to changes in cell volume.

Isosmotic solutions of mannitol, which varied in concentration from 50 to $300 \mathrm{mM}$, were as effective in lowering RVR of the hypoperfused kidney as hypertonic solutions of mannitol or saline. In normally perfused rat kidneys, Blantz (8) has shown that expansion with mannitol solutions, which cause no change in plasma osmolality, resulted in vasodilation of the superficial vasculature. Krishnamurty et al. $(42,43)$ have demonstrated that isosmotic as well as hyperosmotic mannitol is capable of causing vasodilation of arterial smooth muscle from rabbit and cat, and inhibited the vasoactive effects of norepinephrine, electrical stimulation, and elevated extracellular potassium. These observations, although not conclusive, suggest that mannitol may have an effect of vascular smooth muscle independent of its osmotic characteristics.

In present studies, several potent vasodilators, when infused into the renal artery, had no effect on RVR. This is in contrast to studies in the dog which acetylcholine specifically has been shown to lower RVR at reduced perfusion pressures $(31,44)$. Our observations suggest that mannitol may act on the rat renal vasculature by a mechanism totally unrelated to that of other potent vasodilators. The studies of Krishnamurty et al. $(42,43)$ support this hypothesis. These investigators showed that mannitol solutions had a vasodilator effect independent of the mechanism by which substances such as ethacrynic acid caused dilation. Hypertonic

${ }^{4}$ Venkatachalam, M. A. Unpublished observations. saline may act via the same mechanisms or have an unrelated mode of action.

In our previous study (7), we found that expansion with mannitol-containing solutions and HS partially restored GFR and $\dot{V}$. These observations were confirmed in the present study with micropuncture techniques. A complete analysis of the changes in SNGFR was not possible in the present study because all filtration forces could not be assessed in the absence of GFR before expansion (32). However, it seems reasonable to conclude that restoration of GFR is the result of an increase in two determinants of filtration, RBF and net filtration pressure, observed in this study. It is interesting to note that IS expansion, during which RBF remained unchanged and net filtration pressure increased (as a result of a primary reduction in plasma protein concentration), failed to restore SNGFR. This may be due to the fact that a reduction in plasma protein concentration, although it increases net filtration pressure, also appears to cause a reduction in the glomerular ultrafiltration coefficient, an alteration that would impede filtration (45).

In conclusion, $\mathrm{RBF}$ is elevated over control hydropenic values after short periods of perfusion at low pressure. Certain agents, such as mannitol and HS, have the capacity to reduce resistance and restore glomerular filtration under these conditions. Their effect is primarily on preglomerular vessels, although there appears to be some dilation of efferent arterioles as well. The mechanism of this effect may be related to a specific action of mannitol as well as to the osmolality of the solutions employed. The increase in RBF and rise in net filtration pressure are probably responsible for restoration of GFR.

\section{ACKNOWLEDGMENTS}

The authors gratefully acknowledge the secretarial assistance of Ms. Rachel Markiewicz and Ms. Helen Engle.

This research was supported by National Institutes of Health research grant HL 22172.

\section{REFERENCES}

1. Selkurt, E. E. 1945. The changes in renal clearance following complete ischemia of the kidney. Am. J. Physiol. 144: 395-403.

2. Flores, J., D. R. DiBona, C. H. Beck, and A. Leaf. 1972. The role of cell swelling in ischemic renal damage and the protective effect of hypertonic solute. J. Clin. Invest. 51: 118-126.

3. Frega, N. S., D. R. DiBona, B. Guertler, and A. Leaf. 1976. Ischemic renal injury. Kidney Int. 10: S17-S25.

4. Burke, T. J., K. L. Duchin, R. E. Cronin, and R. W. Schrier. 1977. Nephron and microcirculatory pressure changes in norepinephrine-induced acute renal failure: modification by mannitol. Clin. Res. 25: 96A. (Abstr.)

5. Barry, K. G., A. Cohen, J. P. Knochel, T. J. Whelen, Jr., W. R. Beisel, C. A. Vargas, and P. C. LeBlanc, Jr. 1961. Mannitol infusion. II. The prevention of acute functional 
renal failure during resection of an aneurysm of the abdominal aorta. N. Engl. J. Med. 264: 967-971.

6. Beall, A. C., Jr., M. R. Holman, G. C. Morris, Jr., and M. E. DeBakey. 1963. Mannitol-induced osmotic diuresis during vascular surgery. Arch. Surg. 86: 34-42.

7. Morris, C. R., E. A. Alexander, F. J. Bruns, and N. G. Levinsky. 1972. Restoration and maintenance of glomerular filtration by mannitol during hypoperfusion of the kidney. J. Clin. Invest. 51: 1555-1564.

8. Blantz, R. C. 1974. Effect of mannitol on glomerular ultrafiltration in the hydropenic rat. J. Clin. Invest. 54: 1135-1143.

9. Stahl, W. M. 1965. Effect of mannitol on the kidney. Changes in intrarenal hemodynamics. N. Engl. J. Med. 272: 381-386.

10. Wendling, M. G., J. W. Eckstein, and F. M. Abboud. 1969. Effects of mannitol on the renal circulation. J. Lab. Clin. Med. 74: 541-547.

11. Gazitùa, S., J. B. Scott, D. Swindall, and F. J. Haddy. 1971. Resistance responses to local changes in plasma osmolality in three vascular beds. Am. J. Physiol. 220: 384-391

12. Navar, L. G., A. C. Guyton, and J. B. Langston. 1966. Effect of alterations in plasma osmolality on renal blood flow autoregulation. Am. J. Physiol. 211: 1387-1392.

13. Arendshorst, W. J., W. F. Finn, and C. W. Gottschalk. 1975. Autoregulation of blood flow in the rat kidney. Am. J. Physiol. 228: 127-133.

14. Falchuk, K. H., and R. W. Berliner. 1971. Hydrostatic pressures in peritubular capillaries and tubules in the rat kidney. Am. J. Physiol. 220: 1422-1426.

15. Brenner, B. M., J. L. Troy, and T. M. Daugharty. 1972. Pressures in cortical structures of the rat kidney. Am. J. Physiol. 222: 246-251.

16. Sanjana, V. M., P. A. Johnston, W. M. Deen, C. R. Robertson, B. M. Brenner, and R. L. Jamison. 1975. Hydraulic and oncotic pressure measurements in inner medulla of mammalian kidneys. Am. J. Physiol. 228: 1921-1926.

17. Lowry, O. H., N. J. Rosebrough, A. L. Farr, and R. J. Randall. 1951. Protein measurement with the Folin phenol reagent. J. Biol. Chem. 193: 265-275.

18. Allison, M. E. M., E. M. Lipham, and C. W. Gottschalk. 1972. Hydrostatic pressure in the rat kidney. Am. J. Physiol. 223: 975-983.

19. Kashgarian, M., N. J. Siegel, A. C. Ries, H. J. DiMeola, and J. P. Hayslett. 1976. Hemodynamic aspects of development and recovery phase of experimental postischemic acute renal failure. Kidney Int. 10: S160-S168.

20. Snedecor, G. W., and W. G. Cochran. 1967. Statistical Methods. The Iowa State University Press. Ames, Iowa. 6th edition. 419-432.

21. Dunnett, C. W. 1955. A multiple comparison procedure for comparing several treatments with control. J. Am. Statist. Assoc. 50: 1096-1121.

22. Johnson, P. C. (Editor). 1974. Autoregulation of renal blood flow. Circ. Res. 15(Suppl. 1): 103-198.

23. Thurau, K. 1964. Renal hemodynamics. Am. J. Med. 36: 698-719.

24. Rothe, C. F., F. D. Nash, and D. E. Thompson. 1971 Patterns in autoregulation of renal blood flow in the dog. Am. J. Physiol. 220: 1621-1626.

25. Selkurt, E. E. 1963. The renal circulation. Handb. Physiol. 2: 1457-1516.

26. Selkurt, E. E., P. W. Hall, and M. P. Spencer. 1949 Influence of graded arterial pressure decrement on renal clearance of creatine, $p$-aminohippurate, and sodium. Am. J. Physiol. 159: 369-378.

27. Shipley, R. E., and R. S. Study. 1951. Changes in renal blood flow, extraction of inulin, glomerular filtration rate, tissue pressure and urine flow with acute alterations of renal artery blood pressure. Am. J. Physiol. 167: 676-688.

28. Nahmod, V. E., and A. Lanari. 1964. Abolition of autoregulation of renal blood flow by acetylcholine. Am. J. Physiol. 207: 123-127.

29. Navar, L. G. 1978. Renal autoregulation: perspectives from whole kidney and single nephron studies. Am. J. Physiol. Renal Fluid Electrolyte Physiol. 3: F357-F370.

30. Robertson, C. R., W. M. Deen, J. L. Troy, and B. M. Brenner. 1972. Dynamics of glomerular ultrafiltration in the rat. III. Hemodynamics and autoregulation. Am. J. Physiol. 223: $1191-1200$.

31. Baer, P. G., and L. G. Navar. 1973. Renal vasodilation and uncoupling of blood flow and filtration rate autoregulation. Kidney Int. 4: 12-21.

32. Brenner, B. M., J. L. Troy, T. M. Daugharty, W. M. Deen, and C. R. Robertson. 1972. Dynamics of glomerular ultrafiltration in the rat. II. Plasma-flow dependence of GFR. Am. J. Physiol. 223: 1184-1190.

33. Bankir, L., M. M. Trinh Trang Tan, and J. P. Grünfeld. 1979. Measurement of glomerular blood flow in rabbits and rats: erroneous findings with $15 \mu \mathrm{m}$ microspheres. Kidney Int. 15: 126-133.

34. Pouljeol, P., D. Chabardes, J. P. Bonvalet, and C. deRouffignac. 1975. Glomerular filtration rate and microsphere distributions in single nephron of rat kidney. Pfluegers Arch. Eur. J. Physiol. 357: 291-301.

35. Wallin, J. D., R. C. Blantz, M. A. Katz, V. E. Andreucci, F. C. Rector, Jr., and D. W. Seldin. 1971. Effect of saline diuresis on intrarenal blood flow in the rat. Am.J. Physiol. 221: 1297-1304.

36. Folkow, B., and E. Neil. 1971. Circulation. Oxford University Press, London. 14-19.

37. Nygaard, K. K., M. Wilder, and J. Berkson. 1935. The relation between viscosity of the blood and the relative volume of erythrocytes (hematocrit value). Am.J. Physiol. 114: $128-131$.

38. Hermreck, A. S., J. H. Abrams, and R. G. Jones. 1973. Mannitol and propranolol in treatment of ischemic renal failure: improved survival rate and renal function. Surg. Forum. 24: 25-27.

39. Abbott, W. M., and W. G. Austen. 1974. The reversal of renal cortical ischemia during aortic occlusion by mannitol. J. Surg. Res. 16: 482-489.

40. Jamison, R. L. 1974. The role of cellular swelling in the pathogenesis of organ ischemia (Medical Progress). West. J. Med. 120: 205-218.

41. Nosowsky, E. E., and J. J. Kaufman. 1963. The protective action of mannitol in renal artery occlusion. J. Urol. 89: 295-299.

42. Krishnamurty, V. S. R., H. R. Adams, T. C. Smitherman, G. H. Templeton, and J. T. Willerson. 1977. Influence of mannitol on contactile responses of isolated perfused arteries. Am. J. Physiol.: Heart Cir. Physiol. 1: H59-H66.

43. Krishnamurty, V. S. R., R. Adams, G. H. Templeton, and J. T. Willerson. 1978. Influence of mannitol on isolated coronary and peripheral arterial smooth muscle. Clin. Res. 26: 6A. (Abstr.)

44. Gross, R., H. Kirchheim, and K. Brandstetter. 1976. Basal vascular tone in the kidney. Evaluation from the static pressure-flow relationship under normal autoregulation and at maximal dilation in the dog. Circ. Res. 38: 525-531.

45. Baylis, C., I. Ichikawa, W. T. Willis, C. B. Wilson, and B. M. Brenner. 1977. Dynamics of glomerular ultrafiltration. IX. Effects of plasma protein concentration. Am.J. Physiol.: Renal Fluid Electrolyte Physiol. 1: F58-F71. 